\title{
The Influence of Three Variables on the Performance of Personnel in the Private Hospital in Indonesia
}

\author{
Muhammad Hafizurrachman ${ }^{1}$ \\ ${ }^{1}$ Sekolah Tinggi Ilmu Kesehatan Indonesia Maju, Indonesia \\ Correspondence: Muhammad Hafizurrachman, Sekolah Tinggi Ilmu Kesehatan Indonesia Maju, Jl. Harapan No. \\ 50 Lenteng Agung, Jakarta Selatan 12610, Indonesia. Tel: 62-818-120-663.
}

Received: April 28, 2017 Accepted: June 7, 2017 Online Published: June 16, 2017

doi:10.5539/gjhs.v9n9p10 URL: https://doi.org/10.5539/gjhs.v9n9p10

\begin{abstract}
Background: This study aims to look at the effect and its magnitude (value) of the variables: family health history, lifestyle behavior, and work environment on the performance of hospital personnel at the private hospital in Indonesia.

Methods: Cross sectional methods were used in this study and data were analyzed with the approach to SEM using Smart PLS Software. In this study, all services at the hospital were chosen as the unit of analysis with 87 hospital personnel being selected as the sample. Multistage random sampling was used. The research was conducted from January to February 2016.

Results: The results of the analysis showed the performance of hospital personnel in the private hospital was influenced by all the variables which meant that the theoretical model proposed in this study could be implemented. However, none of the variables in the research model showed critical influence, only 8.12 per cent, when compared to variables outside the model which was 91.88 per cent.
\end{abstract}

Conclusion: This study concluded that the three variables studied were not large enough as variables that could be used for interventions in improving the performance of hospital personnel. Therefore, the hospital management needed to look for other variables as effort to improve the performance of hospital personnel.

Keywords: family health history, work environment, lifestyle behavior, performance of hospital personnel, private hospital

\section{Introduction}

In developing countries, one of the main problems in the employment sector is the high rate of personnel turnover (Bonenberger, Aikins, Akweongo, \& Wyss, 2014). It happens regularly with companies, and it is true for personnel in hospitals. This situation can disrupt organizational performance (Dawson, 2014).

Organizational performance can be impaired due to the turnover of employees because replacement of personnel does not mean the same level or better performance to the previous employee who has left the workplace (Dawson, 2014). Many reasons exist, but in general the reasons for leaving can be caused by external and internal factors (Lambrou, 2010). Namely factors related to: work environment, health, and other factors which are the main factors in the hospital (Lambrou, 2010).

Indonesia adopted a law for hospital in 2009 in article 1. Paragraph 1 states that the hospital is a health care institution which organizes personal health services with complete or perfect standard that provide services to inpatients, outpatients, and emergency care (Indonesia, 2009). The statement articulates that Indonesia should have high organizational performance (Guntur, Haerani, \& Hasan, 2012). Provision of high performance at the hospitals can be achieved by the high performance of personnel at the hospitals (Dieleman \& Harnmeijer, 2006). Hence, personnel turnover should be prevented, so that the existence and performance of personnel can always be consistent and further increase over time, through efforts that would improve the individual's performance (Bonenberger, Aikins, Akweongo, \& Wyss, 2014).

Furthermore, different types of personnel involvement, such as working together would produce high hospital performance. Personnel are mainly composed of doctors, nurses, midwives, pharmacists, community health personnel, medical assistants, assistant pharmacists, public health workforce, as well as supporting health 
personnel administration staff, ICT staffs, and maintenance personnel (Fulton et al., 2011).

To an organization, a collaborative work force within the personnel who have been together and along with the availability of the senior personnel will naturally produce optimal organizational performance (Dubois \& Singh, 2009). Therefore, in order to produce optimal hospital services (Kieft, de Brouwer, Francke, \& Delnoij, 2014) for patients, the hospital organization needs to maintain strong cooperation between the senior personnel and other hospital personnel.

Thus, to generate optimal service to patients, the hospital needs to have personnel that have competence, productive and responsive services in order to achieve patience satisfaction (Dieleman \& Harnmeijer, 2006) which will help the hospital management to retain personnel and subsequently increase the number of patient visits.

This means that the recruitment process for the health personnel is very important as it relates to performance. The hospital needs to recruit qualified candidates that are able to perform well in their hospital duties. The performance of health personnel also relates to competence training, job security guarantees, and the perception of health personnel to provide service-based patients' safety (Aiyadh et al., 2014). Indicators related to the performance of hospital personnel are: the ability to set goals, follow work procedures, to have initiatives, ability to work together, to possess individual skills, and to possess professional license.

In addition, other factors that are associated with hospital personnel performance are: leadership, peers, conditions, recognition and factors of reward system (Choudhary \& Puranik, 2014). Work conditions related to performance, is organizational support such as safety procedures, and other supporting regulations (Kaynak, Toklu, Elci, \& Toklu, 2016). The hospital work environment can influence the lifestyle behavior of hospital personnel; this in turn will also affect their performance. Lifestyle behavior can be measured and used as indicators which include: sports activities, eating habits, social activities and maintaining personal hygiene. Hospital work environment indicators also show that it can influence the results of optimal performance which include work rules, work's space, room temperature, noise and lighting.

The ability of a person to produce optimal performance cannot be separated from their health condition and their family's health history which can be learned from the history of physical and psychological status of their parents, their childhood psychological status, lifestyle of their childhood and personal growth and development of their personality. Key et al. provides evidence that if the above health conditions found in the health of the personnel, the performance ability of the personnel will decrease (Key et al., 2004). More over, self-rated health and psychosocial conditions from the work environment, and lifestyle factors influence performance of hospital nurses at work (Vilija Malinauskiene, Palmira Leisyte, 2011).

The aim of this study is to analyze the influence of variables on the history of the personnel's health, hospital work environment, and lifestyle behavior on the performance of hospital personnel at the private hospital in Indonesia.

\section{Methods}

This study used a cross-sectional design. The retrieval of data was held in January to February 2016 in the private hospital. The population was all hospital personnel in the private hospital. The inclusion criteria were hospital employees who had worked a minimum of 6 months, while the exclusion criteria were employees who were on leave or refused to participate in the study.

Sample selection was done by multistage random sampling and obtaining a sample of 87 from 243 personnel at the hospital. Instruments used were in the form of a list of questions (questionnaire), which measured all four variables which were: hospital personnel performance, hospital work environment, lifestyle behavior of hospital personnel and family's health history. The hospital personnel performance variables were measured by three raters (assessors) consisting of a direct supervisor, a team leader, and their colleagues in the hospital. A rater can only assessed a maximum of 5 personnel.

Thus, there were some (personnel) assessed by 2-4 colleagues without assessment by a supervisor or team leader. Three other variables were measured through hospital personnel's subjective perception.

Questionnaire used a scoring system based on the measurement scale of semantic differential with a 1-5 rating scale ratings. A value of 1 was the lowest and 5 was the highest value of a judgment or perception in a question. The number of questions in each variable varied from 6-12 questions.

The Endogen Variable (Dependent) used in the study was hospital personnel performance. Whereas exogenous variables (independent) were: lifestyle behavior of hospital personnel, the hospital work environment and the family's health history of health personnel. The research variables were latent variables. Therefore, to describe a latent variable some indicators were used as an observed variable. 
The four variables had 3-6 indicator variables with a series of the questions. Variables of hospital personnel performance consists of indicators: the ability to set goals, to follow work procedures, to have initiative, to do basic tasks, to be able to work together, to use appropriate working standards. The indicator of the variables of the lifestyle behavior of hospital personnel consists of: sport activities, eating habits, social activities, and maintaining personal hygiene. The hospital work environment variable consists of: indicators like the work rules, the space of work, room temperature, noise and lighting levels. The family's health history variable consists of indicators: the history of physical and psychological status of their parents, their psychological status in their childhood, lifestyle of their childhood and growth and development of their personality.

The validity of the questions tested was done to all the questions about the variables and the reliability of the instruments held in conjunction with the collection of the field data. The validity of the questions on each variable whose value was $<0.423$ was not included in the further calculation process. The study also calculated the value of reliability of the instruments.

Variations of all the answer of the questions on the instruments were tested according to the characteristics of the respondent. This was to determine whether the variations of respondents' answers occurred as a result of the variations on its characteristics of those respondents. Tests were carried out using chi square test with SPSS program. If the value of the chi square test had a value of $p>0.05$ then the questions or statements on such instruments were not influenced by the variations in the characteristics of the respondents.

Data with the concept of Structural Equation Modeling (SEM) were analyzed using software Smart-PLS that produced a measurement model (outer model) complete with a value of Confirmatory Factor Analysis (CFA) and Goodness of Fit (GOF). CFA value was measured by looking at the result of Smart-PLS on the value of lambda (loading factor). Lambda value had to be greater than 0.5 in the loading test, that is to say indicators were a reflection of its variables (Ghozali, 2008). When the lambda value had less than 0.5 , then it had to be retested after the indicators modified on these variables.

Outer loading test (value loading factor) were furnished with ratings on discriminant analysis validity that of assessing indicators reflective of the variable by looking at the value of the cross-loading between the indicator value in the variable and the value of the indicator variable simply reads the value of the Average Variance Extractor (AVE) (Garson, 2016).

The AVE value had to have a value of 0.5 or greater (Ghozali, 2008). Furthermore, if the value of all measurement models were fit, then do an assessment to measure the magnitude of the reliability of each lambda to see the value of composite reliability. Value must be equal to or greater than 0.7 . If the value is less than 0.7 indicators recommended not incorporating them into the model, especially for exploratory models (Chin, Lo, \& Ramayah, 2013). Composite reliability needed to be reinforced with a Cronbach alpha value of each variable to determine the reflective indicator strength level to its variable. Strong relationship must have a value greater than 0.6 (Chin et al., 2013). All of these calculations can be seen in the results of Partial Least Square (PLS).

Structural model's values are the values of the relationships among the variables which were constructed by the model and already had an enough value of goodness of fit. These values can be seen in the calculation of BT or bootstrapping to see the value of the original sample, that is the path value and the value of $\mathrm{T}$ statistics that were significance. The path was significant when the value of $\mathrm{T}$ is greater than 1.44 , namely with an error rate of 15 per cent (Ghozali, 2008).

The next step was to build equations to the model and calculate the value of Q Square or the goodness of fit of the model, which was assessing the magnitude of the variation of research data on to the phenomenon that was studied by calculating R square in each of the variables (Sujit \& Rajesh, 2016).

\section{Results}

The instrument of this study had a reliability of 0.953 (0.952-0.954). The characteristics of all the endogenous variables (independent or dependent) and exogenous (independent) studied had normal distribution of data and were homogeneous. The spread of the characteristics of the respondents is presented in Table 1. 
Table 1. Demographic characteristics of respondents

\begin{tabular}{lll}
\hline Variable & $\mathrm{n}$ & percent \\
\hline Gender & & \\
$\quad$ Male & 10 & 11.5 \\
$\quad$ Female & 77 & 88.5 \\
Educational level & & \\
Diploma III & 58 & 66.7 \\
Bachelor & 29 & 33.3 \\
Marital Status & & \\
Married & 57 & 65.5 \\
Unmarried & 28 & 32.1 \\
Widows and divorce & 2 & 2.4 \\
\hline
\end{tabular}

Source: An-Nisa Hospital, 2016.

Furthermore, testing the distribution characteristics of the respondents with the answers given by the respondents were used bivariate test, with $\mathrm{x}^{2}$ test (Chi Square test). The result obtained showed no variations for the answer of respondents' due to variations in their characteristics, because all test results $\mathrm{x}^{2}$ (chi square test) on each variable has a value of $\mathrm{p}>0.05(0.090-0.416)$. The test results for outer models of at each variable with its indicator, produces CFA with alpha values of $0.56-0.93$ and the value of $\mathrm{T}$ is $2.6-15.6$. GOF measurement model shows the results as shown in Table 2 .

Table 2. GOF value of outer model

\begin{tabular}{lllll}
\hline Variable & AVE & Composite Reliability & Cronbachs Alpha & RSquare \\
\hline Performance of Hospital Personnel & 0.825 & 0.966 & 0.964 & 0.062 \\
Work Environment & 0.524 & 0.844 & 0.789 & 0.122 \\
Lifestyle Behavior & 0.630 & 0.870 & 0.808 & 0.179 \\
Family Health History & 0.703 & 0.904 & 0.858 & 0 \\
\hline
\end{tabular}

Note. Variable Error of Performance 1- ${ }^{2}$ which is 1-0.062 $=0.938$.

Table 2 shows the value of GOF of outer model with a lambda $>0.5$ for all indicators in each variable (0.56-0.93) with significant value of $\mathrm{T}$ (greater than 1.44 or equal to 85 percent level of significance). The validity and reliability was also high (greater than required), then the reading process could be continued for GOF of the inner model (Figure 1). 


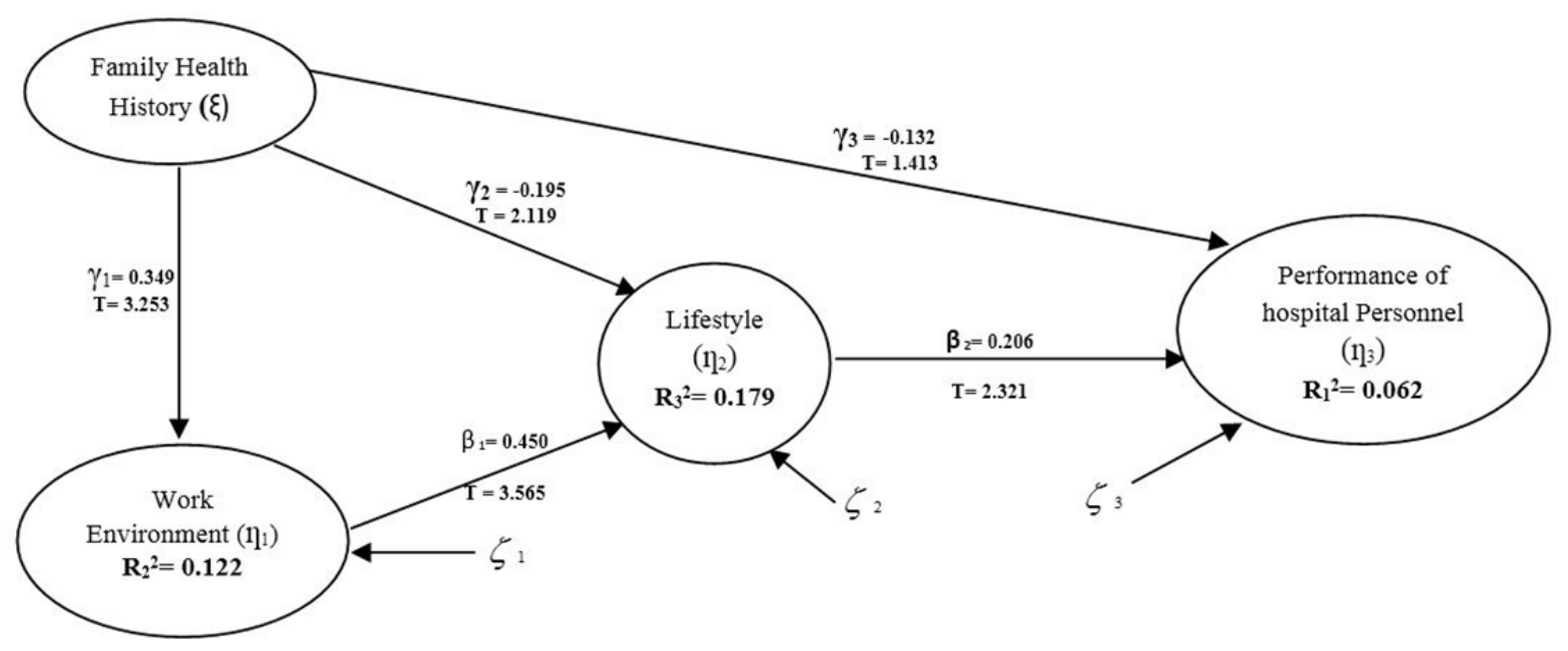

Figure 1.Structural Model - with path/ rho and T value

Source: Data analyzed with PLS and Boostrapping T with Software Smart PLS version 3

Figure 1 the final inner model is a model that has been modified from the initial inner model by the researcher. Modifications needed to be done by eliminating the direct relationship between the work environment and the performance of the hospital personnel. The initial inner model which was proposed had a direct relationship between the 2 above variables. The effect caused the magnitude of the value of the relationship for each variable in the model to have a low $\mathrm{T}$ value, or in other words the calculation in the final inner model (figure 1) gave the value of $\mathrm{T}$ as greater than is presented in Table 3 .

Table 3. Direct value of path/ rho to performance of hospital personnel variables with $t$ value and status of significance on relationships among variables in theStructural Model

\begin{tabular}{lllll}
\hline Relation Between Variable & Original Sample (Rho) & T Value & $\mathbf{H}_{\mathbf{0}}$ & Level Significant \\
\hline Lifestyle -> performance & 0.206 & 2.321 & Fail to reject & Significant \\
environment -> life style & 0.450 & 3.565 & Fail to reject & Significant \\
health_hist-> life style & -0.195 & 2.119 & Fail to reject & Significant \\
health_hist -> environment & 0.349 & 3.253 & Fail to reject & Significant \\
health_hist-> performance & -0.132 & 1.413 & Fail to reject & Significant \\
\hline
\end{tabular}

Furthermore, figure 1 also shows that all the relationships among the variables in the model have a significant relationship to the value of $\mathrm{T}>1.44$ which meant an increase or decrease in the predictor variables on the dependent variable for 1 point. It will increase or decrease the value of rho with the level of accuracy of a minimum 85 percent. Comparison reverse occurs only between the variables of family health history with the performance of hospital personnel, because of its negative rho value.

Moreover, the calculation of the percentage of influence among variables against performances is described in Table 4. 
Table 4. The value of the percentage effect of various variables directly and indirectly to the hospital personnel's performance variable on theoretical model

\begin{tabular}{llllllll}
\hline & LV Correlation & Direct path & $\begin{array}{l}\text { Indirect } \\
\text { path }\end{array}$ & Total & $\begin{array}{l}\text { Direct } \\
\text { percent }\end{array}$ & $\begin{array}{l}\text { Indirect } \\
\text { percent }\end{array}$ & $\begin{array}{l}\text { Total } \\
\text { percent }\end{array}$ \\
\hline Health_hist & -0.140 & -0.132 & -0.0003 & -0.1323 & -13.2 & -0.03 & -13.23 \\
Environment & 0.0264 & N/A & 0.00747 & 0.00747 & N/A & 0.75 & 0.75 \\
Life style & 0.211 & 0.206 & N/A & 0.206 & 20.6 & N/A & 20.6 \\
Health_hist_via & Environt_via & Lifestyle & 0.0000 & 0.0000 & N/A & 0 & \\
\hline Total & & & & $\mathbf{0 . 0 8 1 1 7}$ & $\mathbf{7 . 4}$ & $\mathbf{0 . 7 2}$ & $\mathbf{8 . 1 2}$ \\
\hline
\end{tabular}

The influence of other variables outside the model that can affect performance variable has a percentage value is $100-8.12$ per cent or $\mathbf{9 1 . 8 8}$.

Table 4 shows that the predictive variables (work environment, family health history and lifestyle behavior) gave an effect of 8.12 per cent to the variable performance of hospital personnel. The strength of exogenous and or endogenous variables that were of an independent nature contributed in building an endogenous variable that was of a dependent nature on this theoretical model by looking at the value of $\mathrm{R}$ square on the endogenous variables (Table 2)

The magnitude of the variable error from the variable hospital personnel performances $\left(1-\mathrm{R}_{1}{ }^{2}\right)$ was $(1-0.062)$. It meant that 93.8 percent of hospital personnel performances were affected by other factors than family health history, work environment and life style behavior. The mathematical model equations can be made as follows:

$$
\eta_{3}=\eta_{2} \beta_{2}+\xi_{1} \gamma_{3}+\zeta_{3}
$$

Or

$$
\eta_{3}=0.206 \beta_{2}-0.132 \xi_{1}+0.938
$$

\section{Hospital Personnels Performance $=0.206$ Life Style Behavior -0.132 FamilyHealth History $+\mathbf{0 . 9 3 8}$}

The above mathematical equation model describes the predictive variables which are: the work environment variable, family health history and lifestyle behavior which directly the influence on the hospital personnel performance variable. The value is 6.2 percent. 93.8 per cent is influenced by variables outside the model, including indirect predictor variables on the performance of the magnitude of 2.08 per cent (difference of 8.12 6.20 per cent).

In addition, calculating the value Q-square of used to assess the amount of diversity or variation of research data toward the phenomenon being studied, or can be read as the value of the strength for the confirmation model at the structural models which were delivered or could also be read as the value of predicted relevance at the structural model that was studied as presented in the following:

Q-square Value (Q Square predictive relevance value):

$\mathbf{Q}^{2}=1-\left(1-\mathrm{R}_{1}^{2}\right)\left(1-\mathrm{R}_{2}^{2}\right)\left(1-\mathrm{R}_{3}^{2}\right)$

$\mathbf{Q}^{2}=1-\{(1-0.122) *(1-0.1179) *(1-0.062)\}=0.323854$ or 32.4 per cent

Error Model of $\mathbf{Q}^{2}=100$ per cent -32.4 per cent $=67.6$ per cent

The equation shows a model of the results of the analysis which can explain 32.4 per cent on the diversity of data and the capability of studying the data phenomenon used in the study. Then 67.6 per cent described other components that do not exist in this model. Moreover, the value of Q square can be interpreted as the magnitude of the stability value of the structure of the model for predicting the same structure of the model at other hospitals in which the value was 32.4 per cent.

\section{Discussion}

In general, this study proves that the theoretical model (original concept) which was modified by the researcher, statistically works in this population. Discussions focused on the obtained results, namely the interpretation of statistics that appeared which could give a meaning toward decision making by the management of private hospitals. It could be used as well, as study material at other private hospital in Indonesia, using the variables 
studied.

Which could give meaning in the hospital, the biggest influence on the performance of health personnel is when all variables were given intervention. Lifestyle behavior variables had the largest direct effect among the three variables studied. Despite having the greatest impact in the study, lifestyle behavior variables did not provide sizeable results to impact the performance of health personnel. Variable life style in this study, measured by exercise habits, consumption habit patterns on eating and drinking, social activities, as well as individual and environmental hygiene. The results that had a significant effect on the model did not provide enough value to improve the performance of health personnel compared to the influence of the other variables outside the model, even if in the model all these variables were combined. Results of research conducted by Phiri (2014) states that health personnel who perform a less exercise, are obese in their lifestyle can lead to lower performance (Phiri, Draper, Lambert, \& Kolbe-alexander, 2014). Furthermore, the improvement of a healthy lifestyle behavior of the personnel can be built through awareness of healthy behavior of the personnel by management supported through facility, physical activity by regular exercises (Koolhaas, Brouwer, Groothoff, \& Klink, 2010). Meanwhile, another study also stated that without a healthy lifestyle behavior as indicated by the study, does not have a higher amount effect in percentage on the performance (Rabacow et al., 2014).

The work environment variables in this study were measured by indicators such as the work rules, the space of work, room temperature, noise and lighting levels. The results were influenced indirectly through the path of lifestyle variables on the performance of hospital personnel with the results which were not large enough to support the efforts to improve the performance of hospital personnel in the hospital and so that it can be said that the work environment needed not to be of major concern by hospital management to produce performance. These results were consistent with the research of Kaynak (2016) which stated that the safety procedures, organizational support, and other supporting regulations had an effect on the individual performance (Kaynak et al., 2016). Meanwhile, other studies said that variables of work environment were important to contribute toward the rising of performance such as the study that was done by Chandra and Priyono(Chandra \& Priyono, 2015).

The variable of family health history was the basis for maintaining a better work environment in the generating of performance (Ulrich et al., 2009). Statistically, direct influence of family health history was inversely related to lifestyle and performance by a significant amount. This implies that family history of hospital personnel in the past was not good. It has given good results for the work environment, lifestyle and performance. The consequences of these findings, the researchers found that although the hospital personnel did not have good family health history, it could still yield positive linier results, particularly on the effects of the three variables in the research model such as work environment, lifestyle and performance.

Furthermore, this study showed us that the three variables which were proposed in the model could be supported by other variables outside the model. The results of other studies mention the individual performance was influenced by many factors which were crucial as performance indicators based on the targets' set, following the procedure, the initiative in work, doing basic tasks, the ability to cooperate, and carry out appropriate working standards (Al-Makhaita, Sabra, \& Hafez, 2014; Nelson et al., 2014; Platis, Reklitis, \& Zimeras, 2015).

The result showed improvement whereby ability and skills were necessary to increase the performance of the personnel. Some studies do not include the family history of health personnel as a variable that could influence the performance of the hospital personnel. Besides, to produce high performance level of the personnel needed to be taken into consideration in the recruitment process (Eqab Aiyadh, 2014). Family health history is a variable to be taken into consideration by hospital management during the recruitment process to get new positive personnel.

\section{Conclusion}

Finally, this study confirms that all three measured variables such as family health history, lifestyle, and the work environment did not have a large effect on the performance of hospital health personnel. This suggests that the performance of hospital health personnel was not always affected by variables in the model, but influence greater by the outside research model. The limitation of this study was the amount of sampling that was conducted only at one hospital. However the results could still be applied or generalized to other private hospitals with the same characteristics or class in a matter of hospital accreditations.

\section{Acknowledgements}

The author would like to thank An-nisa Hospital for allowing us to participate in this research.

\section{Competing Interests Statement}

The author declares that there is no competing or potential conflict of interest. 


\section{References}

Al-Makhaita, H. M., Sabra, A. A., \& Hafez, A. S. (2014). Job performance among nurses working in two different health care levels, Eastern Saudi Arabia: A Comparative study. International Journal of Medical Science and Public Health, 3(7), 882-837. https://doi.org/10.5455/ijmsph.2014.240420142

Aiyadh, A. E., Yusoff, R. Z., Alsharqi, O. Z., \& Al-Matari, E. M. (2014). Relationship between high performance work system and patient safety: study on saudi arabia public hospitals. International Journal of Business \& Management, 10(1).https://doi.org/10.5539/ijbm.v10n1p115

Bonenberger, M., Aikins, M., Akweongo, P., \& Wyss, K. (2014). The Effects of Health Worker Motivation and Job Satisfaction on Turnover Intention in Graha. Human Resources for Health, 12(1), 1 . https://doi.org/10.1186/1478-4491-12-43

Chandra, T., \& Priyono, P. (2015). The Influence of Leadership Styles, Work Environment and Job Satisfaction of Employee Performance-Studies in the School of SMPN 10 Surabaya. International Education Studies, 9(1), 131. https://doi.org/10.5539/ies.v9n1p131

Chin, C.-H., Lo, M.-C., \& Ramayah, T. (2013). Market Orientation and Organizational Performance: The Moderating Role of Service Quality. SAGE Open, 3(4), 2158244013512664-. https://doi.org/10.1177/2158244013512664

Choudhary, G. B., \& Puranik, S. (2014). A Study on Employee Performance Appraisal in Health Care. Asian Journal of Management Science, 02(March), 59-64.

Dawson. (2014). Nursing churn and turnover in Australian hospitals : nurses perceptions and suggestions for supportive strategies. BMC Nursing, 1-10. https://doi.org/10.1186/1472-6955-13-11

Dieleman, M., \& Harnmeijer, J. W. (2006). Improving health worker performance : in search of promising practices. Human Resources for Health, (September), 77. Retrieved from http://scholar.google.com/scholar?hl=en\&q=Improving+health+worker+performance:+in+search+of+prom ising + practices\&btnG $=$ Search\&as_sdt $=2000 \& a s \_y l o=\& a s \_v i s=0 \# 0$

Dubois, C.-A., \& Singh, D. (2009). From staff-mix to skill-mix and beyond: towards a systemic approach to health workforce management. Human Resources for Health, 7, 87. https://doi.org/10.1186/1478-4491-7-87

Fulton, B. D., Scheffler, R. M., Sparkes, S. P., Auh, E. Y., Vujicic, M., \& Soucat, A. (2011). Health workforce skill mix and task shifting in low income countries: a review of recent evidence. Human Resources for Health, 9(1), 1. https://doi.org/10.1186/1478-4491-9-1

Garson, G. D. (2016). Partial Least Squares: Regression \& Structural Equation Models. Asheboro: Statistical Publishing Associates.

Ghozali. (2008). Structural Equation Modelling: Metode Alternatif dengan Partial Least Square (PLS). Semarang: Universitas Diponegoro.

Guntur, R. M. Y., Haerani, S., \& Hasan, M. (2012). The influence of affective, continuance and normative commitments on the turnover intentions of nurses at Makassar's private hospitals in Indonesia. African Journal of Business Management, 6(38), 10303. https://doi.org/10.5897/AJBM11.1715

Indonesia, D. (2009). Undang-Undang Nomor 44 Tahun 2009 tentang Rumah Sakit. Jakarta: Republik Indonesia.

Kaynak, R., Toklu, A. T., Elci, M., \& Toklu, İ. T. (2016). Effects of Occupational Health and Safety Practices on Organizational Commitment, Work Alienation, and Job Performance : Using the PLS-SEM Approach. International Journal of Business and Management, 11(5), 1-22. https://doi.org/10.5539/ijbm.v11n5p146

Key, T. J., Schatzkin, A., Willett, W. C., Allen, N. E., Spencer, E. a, \& Travis, R. C. (2004). Diet, nutrition and the prevention of type 2 diabetes. Public Health Nutrition, 7(1A), 147-165. https://doi.org/10.1079/PHN2003586

Kieft, R. A. M. M., de Brouwer, B. B. J. M., Francke, A. L., \& Delnoij, D. M. J. (2014). How nurses and their work environment affect patient experiences of the quality of care: a qualitative study. BMC Health Services Research, 14(1), 1. https://doi.org/10.1186/1472-6963-14-249

Koolhaas, W., Brouwer, S., Groothoff, J. W., \& Klink, J. J. L. Van Der. (2010). Enhancing a sustainable healthy working life: design of a clustered randomized controlled trial. BMC Public Health, 10(1), 461. https://doi.org/10.1186/1471-2458-10-461

Lambrou, et al. (2010). Motivation and job satisfaction among medical and nursing staff in a Cyprus public general 
hospital. Human Resources for Health, 8(1), 26. https://doi.org/10.1186/1478-4491-8-26

Malinauskiene, V., Leisyte, P., Romualdas, M., \& Kirtiklyte, K. (2011). Associations between self-rated health and psychosocial conditions, lifestyle factors and health resources among hospital nurses in lithuania. Journal of Advanced Nursing,67(11), 2383. https://doi.org/10.1111/j.1365-2648.2011.05685.x

Nelson, K., Boudrias, J., Brunet, L., Morin, D., Civita, M. De, Savoie, A., \& Alderson, M. (2014). Authentic leadership and psychological well-being at work of nurses : The mediating role of work climate at the individual level of analysis. Burnout Research, 1(2), 90-101. https://doi.org/10.1016/j.burn.2014.08.001

Phiri, L. P., Draper, C. E., Lambert, E. V, \& Kolbe-alexander, T. L. (2014). Nurses 'lifestyle behaviours, health priorities and barriers to living a healthy lifestyle : a qualitative descriptive study. BMC Nursing, 13(1), 1 . https://doi.org/10.1186/s12912-014-0038-6

Platis, C., Reklitis, P., \& Zimeras, S. (2015). Relation between job satisfaction and job performance in healthcare services. Procedia - Social and Behavioral Sciences, 175, 480-487. https://doi.org/10.1016/j.sbspro.2015.01.1226

Rabacow, F. M., Levy, R. B., Menezes, P. R., Luiz, C., Malik, A. M., \& Burdorf, A. (2014). The influence of lifestyle and gender on sickness absence in Brazilian workers. BMC Public Health, 14(1), 1. https://doi.org/10.1186/1471-2458-14-317

Sujit, K. S., \& Rajesh, B. K. (2016). Determinants of Discretionary Investments: Evidence From Indian Food Industry. SAGE Open, 6(1). https://doi.org/10.1177/2158244016636429

Ulrich, B. T., Lavandero, R., Hart, K. A., Woods, D., Leggett, J., Friedman, D., ... Edwards, S. J. (2009). Critical care nurses' work environments 2008: A follow-up report. Critical Care Nurse, 29(2), 93-102.

\section{Copyrights}

Copyright for this article is retained by the author(s), with first publication rights granted to the journal.

This is an open-access article distributed under the terms and conditions of the Creative Commons Attribution license (http://creativecommons.org/licenses/by/4.0/). 